\title{
Narrativa cinematográfica e realismo indireto: para uma abordagem fenomenológica da narratividade
}

\author{
Filipe Martins \\ IF-UP, ESMAD-IPP \\ E-mail: carlosfilipemartins@gmail.com
}

\begin{abstract}
Resumo
Partindo da análise dos conceitos de narratividade e real, propomos, neste artigo, uma reflexão crítica sobre a tese realista que relaciona a "autenticidade" do cinema com uma recusa da narratividade. A tradição realista que se firmou na teoria do cinema ao longo do século XX (com nomes como Kracauer, Bazin ou Deleuze) defende, geralmente, uma recusa da narrativa e uma valorização do imediatismo das imagens. Existem, no entanto, abordagens alternativas à narratividade que permitem reaproximá-la dos propósitos realistas do cinema e das artes. Pretendemos aqui desenvolver uma dessas abordagens, assente nas seguintes premissas: 1) Os estudos narratológicos e os estudos fenomenológicos da narratividade são es-

fenomenologia permite reinterpretar a narratividade, relacionando-a, num sentido particularmente abrangente, com as noções de performatividade e autoria. 3) A performatividade implica um afastamento do real e da literalidade do real. 4) O cinema está intimamente vinculado à performatividade, mas também reclama uma relação estreita com o real, reconhecível não apenas na natureza intrínseca do próprio suporte (o olho-máquina), mas sobretudo na permanente busca de "autenticidade" por parte dos cineastas e estetas do cinema. 5) Esta aparente contradição - que constitui, na nossa opinião, o cerne do problema estético - pode ser minimizada à luz de um realismo indireto.
\end{abstract} sencialmente distintos, complementando-se. 2) A

Keywords: cinema; real; espelhamento; narratividade; performatividade; autenticidade.

\begin{abstract}
Starting from the analysis of the concepts of narrativity and real, we propose, in this article, a critical reflection on the realistic theory that relates the "authenticity"of cinema with a refusal of narrativity. The realist tradition that has been established in film theory throughout the twentieth century (with names like Kracauer, Bazin or Deleuze) generally defends a refusal of narrative and a valuation of the imme-

diacy of images. There are, however, alternative approaches to narrativity that allow us to reconnect it with realistic purposes of cinema and the arts. We intend to develop one of these approaches, based on the following premises: 1) Narratological studies and phenomenological studies of narrativity are essentially different, complementing each other. 2) Phenomenology allows reinterpreting narrativity, re-
\end{abstract}

Data de submissão: 2018-01-02. Data de aprovação: 2018-09-24.

A Revista Estudos em Comunicação é financiada por Fundos FEDER através do Programa Operacional Factores de Competitividade - COMPETE e por Fundos Nacionais através da FCT - Fundação para a Ciência e a Tecnologia no âmbito do projeto Comunicação, Filosofia e Humanidades (LabCom.IFP) UID/CCI/00661/2013.
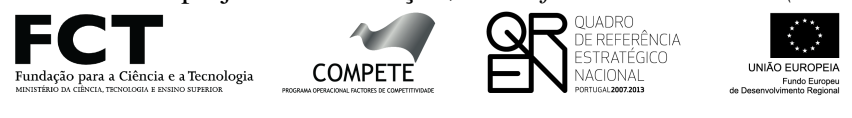

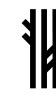


lating it, in a particularly broad sense, with the notions of performativity and authorship. 3) Performativity implies a departure from the real and its literality. 4) Cinema is intimately linked to performativity, but also calls for a close relationship with the real, recognizable not only in the intrinsic nature of the medium itself (the machine-eye), but above all in the permanent search for "authenticity"by filmmakers and aesthetics of cinema. 5) This apparent contradiction - which, in our view, constitutes the core of the aesthetic problem - can be minimized in the light of an indirect realism.

Keywords: cinema; real; mirroring; narrativity; performativity; authenticity.

\section{"Eis por que não há narrativa, eis por que existem tantas".}

Maurice Blanchot (2005, p. 9)

\section{A narratividade e a narratologia}

$\mathrm{O}$ problema ontológico da narrativa tende a escapar à narratologia. Antes de proceder à análise estrutural dos traços de uma narrativa, a narratologia tem primeiro de admitir que está perante um desses objetos, e essa admissão tende a ser ad hoc. Nada nos impede, por exemplo, de analisar um texto noticioso em termos narratológicos (e, de resto, os traços tipicamente narratológicos não serão difíceis de assinalar nesse tipo de discurso). Mas até que ponto uma peça jornalística pode ser considerada efetivamente narrativa? Se qualquer descrição ou organização de informação constitui uma narrativa, onde fica o limite do conceito? ${ }^{1}$

Não é fácil circunscrever o espaço narrativo: a narratividade não se reduz aos processos gerais de organização de informação, nem aos modos específicos de sequenciação temporal dessa informação. Há estruturas e sequências de informação que não são narrativas. Toda a produção discursiva depende de uma articulação entre correlatos, o que aponta para uma estruturação ou um jogo de inferências; mas a construção narrativa não coincide com a própria criação de estruturas discursivas, mesmo quando essas estruturas consistem na descrição de um curso temporal de acontecimentos com relações de causa e efeito. Fazer coincidir os conceitos de narrativa e discurso compromete a especificidade de cada um deles. ${ }^{2}$

1. A título de exemplo: em "Trajetos da Narratividade" (2017, Porto: FLUP), uma publicação recente dedicada à narrativa e aos seus territórios, reúnem-se textos sobre jornalismo, literatura, fotografia, arquitetura, culturas analógicas e digitais, narrativas históricas, ética, sociedade...

2. Christian Metz propôs uma das mais eficazes tentativas de circunscrição da narrativa em termos formalistas. Segundo o autor, a narrativa distingue-se da imagem e da descrição por obedecer a uma "dupla temporalidade". Gaudreault e Jost resumem o seu argumento do seguinte modo: "Uma das funções da narrativa é [segundo Metz] negociar um tempo num outro tempo (...); a narrativa distingue-se da descrição (que negocia um espaço num tempo) e também da imagem (que negocia um espaço num outro espaço)" (Gaudreault \& Jost, 2009, p. 25). Ou, nas palavras do próprio Metz (1968), "o 'plano' isolado e imóvel de uma extensão desértica é uma imagem (significado-espaço $\rightarrow$ significanteespaço); vários 'planos' parciais e sucessivos dessa extensão desértica constituem uma descrição (significado-espaço $\rightarrow$ significante-tempo); vários 'planos' sucessivos de uma caravana em marcha nessa extensão desértica geram uma narração (significado-tempo $\rightarrow$ significante-tempo)". (Citado em Gaudreault \& Jost, 2009, p. 25). Existem várias críticas contra este argumento de Metz: por exemplo, Gaudreault e Jost referem o caráter inevitavelmente temporal da leitura e apreensão das imagens estáticas, ou a dificuldade teórica em distinguir planos sucessivos sobre um tema (o deserto) de planos sucessivos sobre um evento (uma caravana a percorrer o deserto). 
No entanto, certo é que as narrativas continuarão a ser acusadas nos lugares mais insuspeitos: nos relatos históricos, nos textos informativos, nos metadiscursos culturais, nos processos cognitivos ou de organização da memória, nas metodologias e processos de trabalho, nas fotografias, nas pinturas abstratas, na gestualidade da dança. $\mathrm{O}$ termo torna-se tanto mais irrelevante quanto maior a sua aplicabilidade: se tudo for narrativa, de nada nos servirá o conceito.

Mas talvez a aplicabilidade do termo não seja necessariamente sinónima de abrangência ou indefinição. Mais do que uma hegemonização da narrativa e dos seus objetos, a flexibilidade transdisciplinar do conceito parece sugerir que se desvincule a narrativa da natureza intrínseca (e estrutural) dos objetos. A narrativa não estará tanto nas próprias coisas, mas no modo como nos dirigimos a elas. Antes de buscarmos nos objetos (ou discursos) os seus traços distintamente narratológicos, deveremos primeiro interrogar-nos sobre a atitude hermenêutica do intérprete que se presta à leitura de tais objetos.

Ou seja, antes de falarmos de narrativa, falaremos de sentido narrativo enquanto modo interpretativo que, em certa medida, independe do objeto da interpretação. Se o conceito de narrativa remete tendencialmente para a abordagem narratológica (dirigida à estrutura intrínseca do objeto em análise e, porventura, às intenções ou métodos do seu criador), o conceito de sentido narrativo, por seu turno, aponta sobretudo para os processos fenomenológicos de receção. Grande parte dos debates sobre a narrativa podem ser lidos a partir da tensão implícita entre estas duas vertentes metodológicas, que favorecem, respetivamente, a estrutura e função do objeto (na narratologia) ou o papel do intérprete (no estudo dos processos de receção que se ligam à hermenêutica e à fenomenologia) ${ }^{3}$. A problematização da narratividade pode seguir uma análise estrutural (propriamente narratológica) ou fenomenológica. Enquanto a primeira se dedica às questões da forma e da sua eficácia narrativa (no sentido psicológico e respetivo enquadramento sociocultural), a segunda procura delimitar a própria natureza antropológica da narratividade e os seus mecanismos fenomenológicos (onde ainda resistirá, porventura, uma esperança de transculturalidade).

Ao apontarmos esta distinção entre os estudos do sentido narrativo e os estudos narratológicos, não estamos a recusar a possibilidade de um mecanismo singular que descreva a narratividade em geral, pelo contrário. Mas tal mecanismo deverá ser anterior ao enquadramento narratológico, ajudando a fundá-lo. A ontologia da narrativa não está na narratologia, mas na fenomenologia.

É também neste segundo domínio que deverá situar-se o questionamento estético e os fundamentos da eficácia (estética) dos objetos narratológicos. Um estudo verdadeiramente abrangente da narratividade deverá apoiar-se em bases fenomenológicas para explicar o porquê da eficácia das formas narratológicas concretas que participam nas obras de arte. A narratologia limita-se a constatar modelos de eficácia narrativa. Caberá à fenomenologia analisá-los do ponto de vista estético. $^{4}$

3. Esta dualidade de tendências pode ser constatada mesmo no interior da narratologia: por exemplo, nos estudos fílmicos, a valorização que David Bordwell propõe do papel da audiência na interpretação, contra a posição mais formalista de autores como Christian Metz ou Seymour Chatman.

4. Deixamos aqui de fora a psicologia e a sociologia, mais vocacionadas para explicar outras funções e motivações narratológicas. 


\section{O tempo narrativo}

Que mecanismo é esse que descreve fenomenologicamente a orientação narrativa? Uma primeira constatação: todo o sentido consiste em estabelecer relações entre conteúdos, mas, no caso do sentido narrativo, tais relações cumprem sempre uma disposição temporal. É importante, no entanto, não confundir esta temporalidade com aquela invocada para descrever sumariamente a narrativa enquanto sequência temporal de eventos. Nem todas as sequências temporais são narrativas (podem ser simples relatos, descrições, listagens, fluxos de informação); e há, por outro lado, objetos formalmente não-temporais (como as fotografias) que admitem uma leitura narrativa.

O sentido narrativo usa a temporalidade de um modo muito particular: alimentando-se continuamente de um "porvir", entendido aqui como manutenção da distância em relação a uma intenção autoral (ou, se preferirmos, um plano, um desenlace, uma destinação). O porvir é a própria aceitação e preservação da distância em relação a uma solução predestinada. É este porvir que permite que sintamos as mesmas emoções quando assistimos a um filme pela segunda vez, apesar de já sabermos o que irá acontecer. Porque o objetivo não é a informação dos acontecimentos (que podem já ser conhecidos), mas a travessia. Não é o fim (a síntese informativa), mas o intermeio (o fluxo performativo, a performance). Esta manutenção da distância em relação ao que está por vir não é uma fixação no presente, pelo contrário. Em qualquer caso, nunca saímos realmente do presente. Mas o fluxo performativo - o sentido narrativo - não se limita a acompanhar o presente enquanto este decorre ao longo do tempo. O próprio presente torna-se porvir. É uma abertura da temporalidade para lá do devir cronológico.

Podemos reconhecer esta abertura, desde logo, nos processos conotativos, nos sentidos indiretos, nas alegorias: "A nossa existência não é literal (...), ela é uma superação temporal do que é dado no atual em direção a um horizonte possível, por vir. (...) Somos seres criativos que figuramos o mundo" (Kearney, 1984, p. 32). De modo similar, outros autores relacionam a abertura com o regime da "imaginação simbólica" e do "pensamento epifânico". Segundo Gilbert Durand, "O símbolo é uma representação que faz aparecer um sentido secreto, é a epifania de um mistério" (Durand, 2000, p. 12). E acrescenta: “o 'co-nascimento' simbólico, definido triplamente como pensamento sempre indireto, como presença figurada da transcendência e como compreensão epifânica, surge nos antípodas da pedagogia do saber tal como o conhecimento foi instituído desde há dez séculos no Ocidente" (Ibid., p. 20). Para outros ainda, a abertura é sinónima de liberdade (existencial, política, estética); e é também por via dessa abertura ou "ambiguação" que a obra de arte oferece ao espetador um papel participativo. No limite, quando todos os caminhos se equivalem, somos convocados para uma escolha absoluta. Referindo-se ao tom neutral dos filmes do neo-realismo italiano, comentava Amédée Ayfre (1952): "Diante dessa entidade [o filme neorrealista], a atitude do espectador deve mudar radicalmente. Olhar torna-se um ato porque tudo é questionado, respostas são exigidas, ação requerida. É uma convocação da liberdade. É impressionante notar como o cineasta nos coloca frente a frente com o acontecimento humano tomado na sua totalidade, mas abstém-se da fragmentação ou análise, sobrevoando-o simplesmente" (Ayfre, 1952, p. 184). Todas estas perspetivas se regem, de um modo ou de outro, por uma intuição comum: a abertura do presente, o rasgo de incompletude (ou excesso) das formas, que obriga a lê-las em profundidade. 
É também a partir de uma reinterpretação da temporalidade que Blanchot descreve a narrativa, a qual, segundo este autor, pode ser sintetizada através de um único exemplo: "A narrativa é, heroica e pretensiosamente, o relato de um único episódio, o do encontro de Ulisses com o canto insuficiente e sedutor das sereias" (Blanchot, 2005, p. 7). Blanchot considera, como refere André Parente, que o acontecimento narrativo "não se confunde com a sua realização espaçotemporal" (Parente, 2005, p. 258). É um outro tipo de temporalidade, uma abertura do presente, um porvir. Diz Blanchot: "É verdade que Ulisses navegava realmente e, um dia, em certa data, encontrou o canto enigmático. Ele pode, portanto, dizer: agora, isto acontece agora. Mas o que aconteceu agora? (...) Não o acontecimento do encontro tornado presente, mas a abertura do movimento infinito que é o próprio encontro, o qual está sempre afastado do lugar e do momento em que ele se afirma, pois ele é exatamente esse afastamento, essa distância imaginária em que a ausência se realiza" (Blanchot, 2005, p. 12). Uma temporalidade sustentada, portanto, por um princípio de presença-ausência: "A narrativa tem, para progredir, aquele outro tempo, aquela outra navegação que é a passagem do canto real ao canto imaginário, (...) canto enigmático que está sempre à distância e que designa essa distância como um espaço a ser percorrido" (Ibid., p. 11). Este porvir dos acontecimentos da narrativa não se confunde com uma distanciação do presente, ou uma previsão do futuro, ou uma intriga. Tão pouco a narrativa constitui, para Blanchot, o relato de um acontecimento. Pelo contrário, a narrativa é descrita como "o próprio acontecimento, o acesso a esse acontecimento, o lugar aonde ele é chamado para acontecer, acontecimento ainda por vir e cujo poder de atração permite que a narrativa possa esperar, também ela, realizar-se. Essa é uma relação muito delicada, sem dúvida uma espécie de extravagância, mas é a lei secreta da narrativa. A narrativa é movimento em direção a um ponto (...) desconhecido, ignorado, estranho (...), e tão imperioso que é só dele que a narrativa extrai sua atração" (Ibid., p. 8). É neste movimento de aproximação, sempre insuficiente, que o próprio acontecimento narrativo acontece: "Sempre ainda por vir, sempre já passado, sempre presente num começo tão abrupto que nos corta a respiração (...), tal é o acontecimento do qual a narrativa é a aproximação. Esse acontecimento transtorna as relações do tempo, porém afirma o tempo, um modo particular de realização do tempo, tempo próprio da narrativa" (Ibid., p. 13). Coloca-se então a questão: que atrator é esse, capaz de abrir o presente e projetar os acontecimentos para o tempo não-cronológico descrito por Blanchot?

O porvir constitutivo da narratividade sustém-se através da figura do autor. O sentido narrativo assinala um determinado tipo de atitude por parte do recetor - a atitude audiente (no sentido de audiência) -, e essa atitude está ligada, na sua essência, a uma autoria. O intermeio narrativo depende sempre de uma finalidade autoral ${ }^{5}$. O porvir é o cimento de fenómenos como a fé, alimentando a crença na intenção de um autor ou agente responsável pelo destino da narrativa. $\mathrm{O}$ autor assegura um propósito dos acontecimentos, tal como os deuses fornecem um propósito às vidas humanas.

5. Daí que se afirme que a narrativa é fechada (Metz), ao contrário do real, que não terá finalidade. Mas este argumento pode ser invertido: é possível defender que é nos objetos autorais (incluindo as narrativas) que reside a abertura, e não no real, que é sempre lacónico, literal. A arte moderna levou ao limite esta intuição. Nas palavras de Umberto Eco: "Nenhuma obra de arte é de facto 'fechada'; pelo contrário, cada uma encerra, na sua definitude exterior, uma infinidade de 'leituras' possíveis" (Eco, 1989, p. 95). 
A força da assinatura autoral reside na sua dupla condição de presença e ausência. $\mathrm{O}$ autor manifesta-se sempre de forma indireta ${ }^{6}$. Está sempre por vir. O sentido narrativo não se revê, portanto, na troca de informação entre emissor e recetor, mas na relação entre um autor e uma audiência. A primeira relação tende a alimentar modelos informacionais (a começar pelo informacionismo de Shannon ${ }^{7}$ ), a segunda respeita a um tipo específico de atitude interpretativa que remete para a análise fenomenológica ou hermenêutica. O sentido narrativo inscreve-se numa teoria da receção. O conceito de autor, entendido no sentido fenomenológico, é fundamental para a demarcação dos limites da narrativa. Não há sentido narrativo sem um pressuposto de autoria.

Correlativamente, os limites da narrativa relacionam-se com a ideia de orfandade, entendida como ausência de assinatura autoral ${ }^{8}$. O órfão é o casual, o que não é predestinado. Podemos compreender as regras de um sistema órfão, mas não podemos dar-lhe um sentido narrativo. A informação poderá estar bem organizada e os acontecimentos poderão obedecer a uma causalidade escrupulosa, mas essa sucessão de acontecimentos não será narrativa, não terá um porvir. O porvir não tem a ver com o efeito que se segue à causa. É outro tipo de temporalidade. A causalidade está sempre colada ao fechamento do presente, mesmo projetando um futuro ${ }^{9}$. O futuro que se projeta é, afinal, o efeito vinculado à causa, mas essa relação de causa-efeito, por si só, não é sinónima de progressão narrativa. É a autoria que justifica o porvir - a intenção do autor. A autoria cria propósito (em vez de função) e travessia (em vez de trânsito). As coisas com propósito também têm funções, é certo, mas essas funções são actanciais, estão congeminadas, possuem um timoneiro - a origem do mito, da narrativa.

Convenhamos que esta dualidade entre autoria e orfandade não se confunde com a dualidade entre artificial e natural. Um discurso jornalístico é, obviamente, uma produção artificial (com um artífice) mas as regras de construção e apresentação do conteúdo informativo baseiam-se em princípios deontológicos de isenção jornalística que se ligam à tal orfandade fundamental. $\mathrm{O}$ mesmo serve, por exemplo, para discursos epistemológicos como o científico, cujo rigor assenta (supostamente) em mecanismos metodológicos de imparcialidade. Segundo Stephen Heath: "A validade da ciência está em que se presume que ela não tenha autores, que não seja de nenhum modo particular, mas uma demonstração clara e geral da realidade (uma premissa parecida está por trás das conceções convencionais do filme documentário: o cineasta como testemunha - Marker sobre Cuba, por exemplo)" (Heath, 2005, p. 295). A autoria, ao contrário do artifício, não é intrínseca aos discursos, ou teríamos de admitir que todos os discursos são narrativos. A autoria é, antes de mais, um pressuposto de quem recebe e interpreta o objeto discursivo; é este pressuposto

6. O conceito de autoria deve ser aqui entendido num sentido particularmente abrangente, não mundano. Por exemplo, um arbusto em chamas pode ser literalmente um arbusto em chamas ou pode ser experienciado enquanto mensagem divina. Neste último caso, está implicado um autor, o que confere ao arbusto em chamas uma dimensão performativa/comunicativa.

7. Nas suas palavras: “O 'significado' de uma mensagem é geralmente irrelevante” (Shannon, 1993, p. 173).

8. Cf. Martins, 2016, pp. 319-323.

9. Em certa medida, a causalidade (determinista) é atemporal: se já está tudo potencialmente determinado e abstraído a partir do presente, não há necessidade de esperar pelo futuro (como sonhava Laplace). Em contrapartida, o problema da indução descrito por David Hume impõe a temporalidade justamente por desconfiar das relações causais - um ceticismo que, no seu máximo radicalismo, comprometeu todo o aparelho epistemológico do empirismo. 
que predispõe ao sentido narrativo na interpretação. Quando um objeto não pressupõe uma autoria, não pode ser lido narrativamente.

Também interpretamos objetos despojados de autoria, ou seja, que não mereceram esse atributo no ato interpretativo: "Nem todo o discurso tem um autor, nem seria possível exigir que tivesse. Estamos rodeados, na nossa vida quotidiana, por uma trama de discursos em cujos fios entretecidos não saberíamos colocar exigências de autoria" (Heath, 2005, p. 295). O real é construído com objetos (discursos) deste tipo. Segundo Gaudreault e Jost: "Se o 'real' não é proferido por ninguém, a fortiori ele 'jamais conta histórias'. Isto é, a partir do momento em que lidamos com uma narrativa, sabemos que ela não é o real" (Gaudreault \& Jost, 2009, p. 26). Tais objetos do real estão condenados a ser lidos literalmente. Não há conotação ou performatividade nos objetos órfãos. O sentido literal é a alternativa ao sentido narrativo. Do ponto de vista fenomenológico, o real (a não confundir com a realidade acessível epistemologicamente) é a construção que fazemos de um mundo literal. O real é órfão, é o devir sem o porvir. ${ }^{10}$

\section{O cinema e o espelhamento do real}

Tudo isto sugere que o sentido narrativo (que é o domínio da performatividade), nos afasta, por definição, do real (que é o domínio da informatividade). É sabido, no entanto, que grande parte da teoria da arte aposta no realismo, contra a abordagem formalista. É, aliás, devido ao desencontro entre a narratividade e o real que tantos teóricos realistas defendem uma incompatibilidade essencial entre a expressão narrativa e o valor artístico. Na teoria do cinema do século XX, noções como a de "enredo encontrado" (Kracauer), "ambiguidade" (Bazin) ou "imagem-tempo" (Deleuze) apontam, cada uma à sua maneira, para uma purgação dos enredos no cinema e para um retorno ao real. Não falamos aqui, evidentemente, do "realismo ilusório" usado em Hollywood através de técnicas como a "montagem invisível", mas de uma efetiva rarefação das estruturas narrativas, seja pela passividade do cineasta, pela fragmentação, pelo minimalismo ou pela ausência de tema, convenção ou mensagem unívoca.

Apesar da sua relação próxima com as estruturas narrativas, o cinema rapidamente se impôs como modelo por excelência desta viragem estética, alimentando linhas divisórias antigas como a que separa a imagem da linguagem (expressa, nomeadamente, na demarcação recorrente entre o cinema e a literatura). Segundo Rancière, o que o romancista escreve "não é aquilo que ele vê e é justamente este intervalo que faz com que haja literatura. Com o cineasta passa-se de outra maneira: aquilo que ele vê, o que está diante da câmara, é também aquilo que o espetador

10. Em termos fenomenológicos, dizer que o real é órfão (ou seja, desprovido de autoria) implica abdicar do sujeito. Tal não quer dizer que este real prescinda então de uma intencionalidade. A consciência fenomenológica é sempre consciência de alguma coisa (fórmula usada por Brentano e Husserl para descreverem a intencionalidade), mas não é sinónima de sujeito, seja no seu sentido transcendental (como decretaram os pós-metafísicos), seja enquanto processo hermenêutico de subjetivação. Pode haver intencionalidade sem subjetividade. O real fenomenológico é a-subjetivo. Só na adesão à performatividade - suportada pelo pressuposto de uma intenção autoral - é que a consciência assume uma intencionalidade subjetiva. No sentido literal, a consciência dirige-se intencionalmente a um objeto, incorporando-o; no sentido narrativo, a consciência dirige-se intencionalmente a um sujeito, incorporando-o. É a diferença entre apreender (informativamente) um estado de coisas ou aderir a um papel (performativamente). Sobre este conceito de subjetivação, cf. Martins, 2016, pp. 291-311. 
irá ver" (Rancière, 2013, p. 43). A imagem cinematográfica gozará, então, de uma condição privilegiada de imediaticidade. Mas essa condição é esquiva, devendo ser gerida ativamente para que o cinema não se perca nos vícios da narrativa. Prossegue Rancière: "Também [para o cineasta] existe a escolha entre duas maneiras de ver: a relativa, a que instrumentaliza o visível ao serviço do encadeamento das ações, e a absoluta, aquela que dá ao visível o tempo de produzir o seu próprio efeito" (Ibid.).

Não parece fácil alcançar esta "maneira absoluta de ver", que resultará, afinal, da depuração do sensível ou do plano intensivo (por oposição à narrativa, à figuração, à representação). No caso do cinema, Deleuze situou historicamente no pós-guerra a mudança de paradigma no sentido de uma maior recusa da narrativa e da representação. "Se, para a semiologia do cinema, a linguagem do cinema se define pela sua natureza narrativa (narratividade), para os teóricos dos movimentos do cinema do pós-guerra, o cinema só poderia ser definido em oposição à narrativa como sistema de representação" (Parente, 2005, p. 253). Rancière refere, por exemplo, o cinema de Bresson apontado por Deleuze como um caso paradigmático -, onde a "fragmentação" da ação através de planos independentes é "destinada a afastar o perigo da representação" (Rancière, 2012, p. 22). Nas palavras do próprio Bresson, "ela [a fragmentação] é indispensável se não se quiser cair na representação. Ver os seres e as coisas nas suas partes separáveis. Isolar essas partes. Torná-las independentes" (Bresson, 1995, pp. 93-94). No entanto, contrapõe Rancière, "não é assim tão certo que a fragmentação praticada por Bresson obedeça a um princípio anti-representativo. Porque no âmago da lógica representativa está a ideia do todo, onde as partes se encontram exatamente ajustadas" (Rancière, 2012, p. 67).

O desafio anti-representacionista não é, de resto, exclusivo do cinema (onde mais claramente colidem as dimensões da imagem e da linguagem, do sensível e do narrativo). Para Deleuze, toda a arte, e não apenas o cinema, caminha no sentido de uma superação das histórias e das representações. Referindo-se à pintura de Francis Bacon, Deleuze nota que "quando [Bacon] avalia os seus próprios quadros, afasta-se daqueles que são demasiado 'sensacionais', porque a figuração que neles subsiste reconstitui, ainda que secundariamente, uma cena de horror e reintroduz desse modo uma história para ser contada: mesmo as corridas de touros são demasiado dramáticas. Logo que haja horror há uma história que é reintroduzida e o grito resulta falhado. (...) À violência do representado (o sensacional, o cliché) opõe-se a violência da sensação" (Deleuze, 2011, pp. 8586). Será essa, então, a (difícil) tarefa do artista: "Acima do tempo cronológico das causas que agem nos corpos, [o artista] institui um outro tempo, ao qual Deleuze dá o nome grego de aion: o tempo dos acontecimentos puros. O que a arte faz, em geral, e a montagem cinematográfica, em particular, é arrancar aos estados dos corpos as suas qualidades intensivas, as suas potencialidades que descrevem apenas os acontecimentos" (Rancière, 2014, pp. 181-182).

O conceito bergsoniano de "duração" 11 ocupa um papel central na teorização de um "regime estético da arte", por oposição ao "regime representacional" (para usarmos aqui as designações de Rancière). Deleuze e Guattari falam de "sensação" para referirem esse plano que a arte se propõe

11. Cf. Bergson, 1988. 
explorar ${ }^{12}$ : um plano que só pode emergir mediante a neutralização do vivido e da subjetividade humana. A sensação ("afeto", "percepto") como pura presença da matéria desnudada, imediata.

Este tipo de realismo imediatista pode manifestar-se de formas diversas na expressão artística: por via da fragmentação (a interrupção das relações internas entre as partes, como no cinema de Bresson): ou a deformação (a "passagem pelo caos", como descreve Deleuze ${ }^{13}$ ); ou a passividade (o recuo do artista perante o real, para não o desvirtuar ${ }^{14}$ ); ou ainda a simplicidade formal (que evita jogos relacionais entre as partes, anulando a insinuação de conteúdo ${ }^{15}$ ). Em qualquer dos casos, o acesso ao real concreto prende-se com algum tipo de imediaticidade: o objetivo da arte será a relação direta com a matéria, sem significação, sem os vícios ou preconceitos percetivos da subjetividade do artista.

Compreende-se, nestes termos, o apelo especial do dispositivo cinematográfico. Com ele a matéria e a imagem da matéria parecem confundir-se. Na impressão de luz do cinema, a imagem reflete a matéria, mas sem a trair. Em rigor, é a própria matéria que se desdobra. Uma "divisão originária" da matéria, como dirá Bragança de Miranda: "A divisão originária, materialmente considerada, é a da matéria ela mesma quando se reflete ou desdobra. É a divisão da Physis por reflexo, ainda antes de haver qualquer 'sujeito' ou 'consciência'" (Miranda, 2012, p. 29). Partindo desta originariedade da divisão por espelhamento, prenuncia-se no cinema a sua capacidade de ver mais do que o olho humano, mesmo sendo o olho humano a apontar a objetiva: "No princípio do cinema está um artista 'escrupulosamente honesto', um artista que não faz batota, que não pode fazer batota, uma vez que ele apenas regista. Mas esse registo não é já a reprodução idêntica das coisas, na qual Baudelaire via a negação da invenção artística. Ao modificar o próprio estatuto do 'real', o automatismo cinematográfico regula a querela entre a técnica e a arte. Não reproduz as coisas tal como se oferecem ao olhar. Regista-as tal como o olho humano não as vê, tal como surgem ao ser, no estado de ondas e de vibrações, antes da sua qualificação como objetos, pessoas ou acontecimentos identificáveis pelas suas propriedades descritivas ou narrativas" (Rancière, 2014, p. 9). Não se tratará, portanto, de apontar a fidelidade do olho cinematográfico perante o real, mas de revelar todo um mundo insuspeito que antecede ou escapa à representação. Intuição que acompanha o cinema desde a sua infância. Nas palavras de Jean Epstein: "o olho da câmara é um olho sem preconceitos, sem moral, abstraído de qualquer tipo de influências, e que vê no rosto e no movimento humanos certos traços desconhecidos que nós, carregados de simpatias e antipatias, de hábitos e reflexões, não sabemos ver" ${ }^{16}$. O cinema, então, como espelhamento direto da matéria, sem passagem pelos processos fenomenológicos de representação ou pela organização subjetiva.

Mas como é que um espelhamento pode não ser representação? Como é que uma imagem pode ser figural (Lyotard) ${ }^{17}$ sem ser figurativa? Desde logo, evitando o olhar fenomenológico

12. Cf. Deleuze \& Guattari, 1992.

13. Cf. Deleuze, 2011.

14. Máxima de Rosselini: “As coisas estão aí (...). Porquê manipulá-las?”. [Citado em Monteiro, P. F. (1996). Fenomenologias do Cinema. In Revista de Comunicação e Linguagens 23. O que é o Cinema? (pp. 61-112). Lisboa: Edição Cosmos].

15. Veja-se, por exemplo, a obra de Donald Judd e outros minimalistas americanos dos anos 60.

16. Epstein, Jean (1926). Le Cinématographe vu de L'Etna. (Citado em Grilo, 2012/2017, p. 59).

17. Cf. Lyotard, 1971. 
e mergulhando na fisiologia do mundo. Veja-se, por exemplo, a seguinte passagem de Lacan a propósito da imagem: "Uma imagem significa que os efeitos energéticos que partem de um dado ponto do real - imaginem-nos como sendo da ordem da luz, pois é isso que mais manifestamente evoca a imagem no nosso espírito - vêm refletir-se num ponto qualquer de uma superfície, vêm bater no mesmo ponto correspondente do espaço. A superfície de um lago pode perfeitamente ser substituída pela área estriada do lobo occipital, pois a área estriada, com as suas camadas fibrilares, é muito semelhante a um espelho. Da mesma forma que não precisamos de toda a superfície de um espelho - se é que isto quer dizer alguma coisa - para nos apercebermos do conteúdo de um campo ou de um quarto, pois podemos fazê-lo manipulando um fragmento de espelho bem pequeno, também uma qualquer pequena secção da área estriada serve para o mesmo efeito, comportandose como um espelho. Muitos tipos de coisas no interior do mundo comportam-se como espelhos" (Lacan, 1978, p. 65).

Nesta descrição de Lacan, nunca chegamos a descolar da fisiologia. A "área estriada do lobo occipital", que atua como espelho, pertence ainda inteiramente à Physis, mesmo situando-se no cérebro orgânico, tal como a superfície do lago ou a película fotográfica. $O$ espelho não chega a instalar-se no seio de uma consciência fenomenológica. Para que a Physis produza imagens de puro espelhamento, é preciso contornar o plano fenomenológico, onde qualquer dobra já não seria apenas espelhamento, mas representação, imagem mental. Por outro lado, sem uma âncora fenomenológica, tais espelhos tendem a perder-se no magma da Physis, multiplicando-se ao infinito. É preciso olhar para o espelho, concretizá-lo como tal, torná-lo utensílio. Os espelhos que nos interessam são objetos técnicos. "O espelho é a máquina arcaica por excelência, contendo todas as máquinas "futuras"” (Miranda, 2012, p. 31). Como a máquina cinematográfica. Todas as máquinas - todos os espelhos técnicos - requerem um olho humano: é esse o princípio da techné. $\mathrm{O}$ cinema também faz as suas escolhas. Até o espelho de Lacan tem de ser manipulado.

Dir-se-á que as imagens desse espelho técnico - do cinema, em particular - ensinam o olho humano a ver exatamente o que o próprio espelho vê. Nesta perspetiva, o olho humano, transportando-se para o espelho, vislumbrará o real espelhado com o mesmo imediatismo ou a mesma neutralidade figural do próprio espelho - mas será ainda um olhar humano. De facto, para Jean Epstein, o cinematógrafo era o instrumento do "infinitamente sincero", do "infinitamente humano", tal como o telescópio remete para o infinitamente grande ou a lupa remete para o infinitamente pequeno. Esta ampliação do humano, viabilizada pelo cinema, teria afinal a ver com a isenção do olhar, com a afinação de um olhar mais puro, de modo a alcançar uma paisagem mais humana (ou, se preferirmos, uma mais autêntica incorporação do humano na paisagem). Em última análise, é a própria ilusão do humano em relação a si próprio que é desmascarada no cinema, tornada visível na confrontação entre os nossos vícios subjetivos e o puro espelhamento objetivo (como quando estranhamos o nosso rosto ou a nossa gestualidade filmada). A imagem cinematográfica, no dizer de Epstein, como "a fotografia das ilusões do coração".

Em certa medida, quase parece contraditório que seja o mesmo Epstein a afirmar que "em geral, o cinema conta mal a história. E, nele, 'ação dramática' equivale a erro. (...) O cinema é verdadeiro. Uma história é uma mentira" (Epstein, 1974, p. 86). Como pode este espelho ser tão isento, tão desprovido de narrativa, e ao mesmo tempo tão humano? Até que ponto o olho humano pode colocar-se no lugar do espelho, reduzindo-se à sua neutralidade, à isenção 
da "divisão originária da matéria"? Em suma, como pode o olho cristalizar-se? Não estará ele condenado a uma distância mínima em relação ao espelho, tal como já estava - assim o acusam os imanentistas - condenado a uma distância em relação ao real? E como é que podemos estar certos de reconhecer o autêntico através do espelho? Como é que o espelho, que é um elemento mediador, pode diminuir a distância entre o olho e o real (ou o "verdadeiro", ou o "autêntico"), em vez de provocar, ao invés, uma dupla distanciação? Afinal, como nota ainda Bragança de Miranda, "apesar da enorme evidência do espelho, este é sempre segundo, é uma mecânica para produzir artificialmente o reflexo" (Miranda, 2012, p. 31). Não ditará o espelho, enquanto techné, a inevitabilidade de um olho fenomenológico, um operador das imagens, um autor? Não estaremos ainda plenamente no domínio do sentido, ou mesmo do sentido narrativo?

\section{Realismo indireto}

As diferentes formas de entendimento da arte no seu relacionamento com o real são tanto mais problemáticas quanto mais apontam para algum tipo de imediatismo ou purismo sensológico. Desde logo, parece que a arte não pode ser relacionada com o real em termos de verosimilhança, fidelidade percetiva ou imediatismo formal. Mas as versões imanentistas ou materialistas do realismo também se deparam com as mesmas dificuldades. A relação imediatista com o real acaba sempre por conduzir às dificuldades típicas das teorias miméticas e literalistas da arte: ou a arte é mera imitação, ficando sempre aquém do real, ou é mera amostragem do real (o que a torna trivial), ou alcança a ilusão absoluta, confundindo-se com o real, o que a torna dispensável ou, pior ainda, alienadora. Conclui Rancière: "Se o cinema não confirmou a promessa de uma nova arte anti-representativa, talvez não tenha sido por submissão à lei do comércio. É que a própria vontade de o identificar com uma língua da sensação era contraditória" (Rancière, 2012, p. 20). Curiosamente, Rancière situa a contradição precisamente no facto de o cinema, por definição, ser imediato. O cinema "mostra o que mostra" (ibid.). De modo que o objetivo do cinema, enquanto arte, terá então de ser outro, ou transformar-se-ia "num pleonasmo" (ibid.). Em última análise, este argumento é apenas um outro modo de apontar a inconsistência dos manifestos literalistas ou imediatistas da arte cinematográfica.

Para que a arte se justifique, a relação com o real não pode ser absoluta. O sentido da obra não pode ser absolutamente literal. Tem de haver um aspeto específico da apropriação do real que não se confunda com o que é evocado por outros discursos sobre o real (como o registo jornalístico, por exemplo). Um objeto fílmico literal não será cinema, mas um mero objeto informativo. É necessário preservar uma certa distância à literalidade. Não quer dizer que a arte não tenha em vista o real. Há na arte uma busca da autenticidade que é inegável, mas esta autenticidade não é um sentido literal. A interpretação literal nunca é estética. A relação da arte com o real, por mais imperativa que seja, tem de manter-se, de algum modo, indireta.

No entanto, os realismos artísticos tendem a ser diretos: o realismo mimético (que converge com o naturalismo, com o aperfeiçoamento das aparências, facilitando a imersão direta nos simulacros ${ }^{18}$ ); o realismo literalista (que se atém à imediaticidade da forma concreta, não significante,

18. É certo que este realismo mimético é representacional, mas nem por isso deixa de ser um realismo direto. Na sua vocação naturalista, este realismo opõe-se ao idealismo nos mesmos termos descritos na alegoria da caverna de 
em detrimento do conteúdo - ou do significado -, propondo, deste modo, uma curiosa convergência com o formalismo); ou o realismo imanentista (que se propõe reabilitar, através da obra de arte ou de um posicionamento estético, o acesso direto à matéria sensível que antecede a representação).

O realismo direto, em qualquer uma das suas versões, torna-se mais problemático quando tentamos extrair dele orientações concretas para as práticas artísticas. Um exemplo emblemático é o de André Bazin, que defendeu um realismo ontológico do cinema - descrito como "a arte do real" - a partir da reflexão sobre a sua matéria-prima: a imagem fotográfica. Segundo Bazin, a fotografia não representa o real, uma vez que consiste no resultado de um processo mecânico que é prolongamento do próprio real. Não se trata de valorizar a acuidade da fotografia na sua reprodução de determinado objeto (a fotografia pode parecer irreal), mas do próprio pressuposto do espetador de que se trata de uma imagem fotográfica, uma impressão de luz. Nas palavras de Bazin, "a fotografia goza de determinada vantagem em virtude dessa transferência da realidade da coisa para a sua reprodução" (Bazin, 1967, p. 71). Através desta transferência ou imediatismo, o cinema parece escapar ao problema platónico da imitação ou representação. Mas o argumento não afasta a questão: o que é que a fotografia (ou o frame) acrescenta ao seu objeto? A intuição de Bazin está correta ao prever um aspeto psicológico do realismo fotográfico e cinematográfico: a crença inata do espetador no real enquanto origem da imagem. Há um pressuposto de leitura que tem de ser estabelecido por parte do espetador para que o cinema revele a sua natureza realista. Mas o realismo do cinema, ou o seu pressuposto, não parece ser suficiente para justificar a sua função. Para que servirá o cinema e o seu realismo se um real muito mais amplo estiver logo ali à saída da sala de cinema? ${ }^{19}$

Para Bazin, é o realismo do cinema que lhe restitui o seu aspeto cinemático e o seu valor como arte autónoma. É um postulado estético. Deleuze estendeu esse postulado à arte em geral (e a todo um domínio do sensível) a partir do cinema. A relação do fenómeno estético com o real é um lugar comum que atravessa toda a teoria da arte. No entanto, mesmo no realismo de Bazin, a distância ao real permanece lá, no próprio veículo mediador: a imagem fotográfica. A fotografia (artística) designa um ato performativo, mesmo que, por outro lado, a fotografia já convide, pela própria natureza do dispositivo, a retornar ao real.

Bazin fala de "ambiguidade" para descrever o "autoafastamento do artista" e o foco na "virgindade incipiente da matéria-prima". Referindo-se a De Sica: "Os eventos não são necessariamente signos de alguma coisa, uma verdade sobre a qual devemos ser convencidos, todos têm o seu próprio peso, a sua singularidade completa, aquela ambiguidade que carateriza qualquer facto" (Bazin, 1971, p. 52). A ambiguidade é assumida como característica da própria realidade percetiva, devendo deduzir-se daí os processos adequados do cineasta para deixar falar o real. Bazin defende, por exemplo, a atitude passiva ou o estilo neutro, de modo que a perspetiva do cineasta

Platão: o que vemos diretamente não são as ideias, mas as sombras projetadas (as quais, por força da imersão, não reconhecemos como tal).

19. Dir-se-á que o objetivo é, na verdade, intensificar o real, isto é, alcançar um "real mais real que a realidade comum" (Ricoeur, 2009, p. 62). Mas esta solução contém as suas próprias dificuldades. Além de não ser suficientemente abrangente e acabar por contrariar o próprio realismo, a tese do "aumento icónico" da realidade convida a incorporar caraterísticas como o sensacionalismo, o sentimentalismo, etc. 
não comprometa a virgindade do real. A ambiguidade joga bem com a passividade. Por outro lado, o excesso de ambiguidade confunde-se com a arbitrariedade. No contexto artístico, um traço arbitrário pode funcionar como um descuido, um efeito de dispersão, revelando gratuitidade ou falta de estrutura, para usarmos alguns dos termos mais recorrentes na crítica de arte. Há um sentido de necessidade que impõe limites ao arbitrário e à ambiguidade na apreciação estética. Este excesso de ambiguidade mostra-nos que a premissa realista não se prende apenas com as caraterísticas atribuídas ao real, mas com o modo como o real deve ser trabalhado pelas poéticas dos cineastas. Se a ambiguidade fosse um traço inequívoco do real, nunca poderia ser excessiva no âmbito de uma teoria realista do cinema.

Por outro lado, a própria ambiguidade também pode ser trabalhada para combater caraterísticas tipicamente associadas ao realismo, como a imersividade. Bastaria aqui referir o formalismo de Brecht, por exemplo ${ }^{20}$. E há formas de realismo que também podem recusar a ambiguidade, como a linguagem clássica do cinema americano, que visa a imersividade do espectador através de técnicas naturalistas como a "montagem invisível". Evidentemente, não é este tipo de realismo que interessa a Bazin ${ }^{21}$. Mas isto revela contradições internas no próprio discurso realista. A ambiguidade combate a imersividade, mas tanto uma como a outra podem ser associadas a um tipo de realismo.

Estes exemplos revelam algumas das imprecisões em que a teoria realista do cinema pode incorrer. Há diferentes caraterísticas realistas que colidem entre si no âmbito da arte. Talvez, então, seja mais conveniente não relacionar figuras como a ambiguidade, a arbitrariedade ou a imersividade diretamente com o real, nem definir tais figuras como intrinsecamente realistas (pelo menos, não no sentido que convém ao realismo estético). O vínculo da arte ao real, que nos parece indiscutível, não pode ser descrito através da classificação e catalogação de figuras realistas específicas, diretamente acessíveis. O plano-sequência ou a profundidade de campo (técnicas defendidas por Bazin) não constituem, seguramente, fórmulas inequívocas de acesso privilegiado à autenticidade do real. O real não é um conjunto de caraterísticas formais intrínsecas, nem se confunde com a realidade fisiológica acessível empiricamente. Mesmo assumindo que a realidade é intrinsecamente ambígua, essa sua caraterística formal colocaria o cinema na posição de imitar ou representar um aspeto da realidade, devolvendo-o às dificuldades das teorias miméticas ou literalistas da arte.

A arte não é realista, no sentido em que não lhe basta reproduzir ou alcançar ou sintonizar o real (ou os traços típicos da sua autenticidade). Quando muito, poderemos falar de um realismo indireto na arte.

\section{Entre a narratividade e a literalização}

A fenomenologia - que, em tempos, tendia para alguma forma de imediatismo (o cogito cartesiano, a "presença a si do presente vivo" de Husserl, a "náusea" existencial de Sartre) - confunde-

20. Cf. Brecht, 1978; e Benjamin, 1998.

21. Bazin (1958) não hesita em apontar a "confusão entre o estético e o psicológico, entre o verdadeiro realismo, que implica exprimir a significação a um só tempo concreto e essencial do mundo, e o pseudo-realismo do trompe l'oeil (ou do trompe l'esprit), que se contenta com a ilusão das formas" (Bazin, 1983, pp. 123-124). 
se cada vez mais com uma hermenêutica, com um processo interpretativo, admitindo, portanto, um primado da mediação. A "fenomenologia não pode constituir-se sem um pressuposto hermenêutico" (Ricoeur, 1986, p. 50). Tais processos fenomenológicos serão certamente analisáveis, ou mesmo sistematizáveis, mas não necessariamente num sentido estruturalista. A via fenomenológica é distinta da via estruturalista, embora os mecanismos fenomenológicos também condicionem, a um nível fundacional, os modos de organização das estruturas objetivas que perfazem o plano da cultura, incluindo as estruturas com propósitos estéticos, como as composições cinematográficas ou outras formas de expressão narratolológica ou artística.

Como vimos, o domínio fenomenológico, assim entendido, admite duas orientações distintas do sentido (assumindo-se aqui o sentido, antes de mais, como movimento do pensamento): um sentido orientado para o real (o sentido literal, que se liga ao regime informativo) e um sentido orientado para a intenção autoral (o sentido narrativo, que se liga ao regime performativo). Este princípio diferenciador pode ser-nos útil para uma compreensão do realismo indireto no contexto estético.

O real fenomenológico é o desvelamento de um sentido literal, mas a literalidade não interessa à arte. Pelo contrário: quando a obra de arte falha, não é por se ter desviado do real, mas porque se literalizou (isto é, porque renunciou à performatividade). Esta literalização poderá assumir várias formas perante um objeto artístico. Há, em primeiro lugar, o perigo de literalização da obra, a redução desta à sua dimensão objetiva, informativa, órfã. Isto pode ser motivado, desde logo, por um défice contextual (por exemplo, o urinol de Duchamp fora de contexto) ou pela falta de competência de leitura (o espetador que não conhece os códigos para uma interpretação apropriada ou para o reconhecimento dos traços autorais). Em condições adequadas de leitura (como num espaço de exposição), a literalização da obra será motivada pela própria estrutura intrínseca do objeto, ou melhor, a sua falta de estrutura. O défice estrutural pode traduzir-se num excesso de casualidade ou subtileza dos traços de congeminação autoral. Em suma, uma arbitrariedade. Nestes termos, a sonoridade tenderá para o ruído e a composição tenderá para o caos, impedindo que a obra instale um espaço performativo, ou, pelo menos, a adesão do espetador a esse espaço. O crítico falará porventura de dispersão, gratuitidade ou falta de coesão.

Em segundo lugar, a literalização da intenção autoral. Este é o caso que melhor reflete a crítica platónica da cópia (ou da cópia da cópia), enquanto denúncia do falso. Quando a operação do artista se sobrepõe ao seu objeto, ofuscando-o, dá-se um desmascaramento da operação. De algum modo, a execução do artista chamou demasiado a atenção para si própria e a obra tornou-se forçada, artificial, construída, uma tentativa falhada, como um passe de magia em que descobrimos o truque de antemão. Uma artificialidade. Quando, perante uma obra, denunciamos o cliché, o kitsch, a previsibilidade, a conveniência, o naïf amadorista, a adjetivação forçada, etc., estamos, de algum modo, a desmascarar a operação do autor, literalizando-a.

Em terceiro lugar, a literalização do conteúdo performativo: o alheamento, por parte do espetador, da condição de habitar um espaço performativo. Neste cenário, após uma adesão inicial, a experiência performativa é interrompida porque o simulacro foi entretanto confundido com o real, desresponsabilizando o intérprete, alienando-o, desligando-o do seu papel participativo. Uma 
imersividade. Para autores como Brecht, reside aqui a ameaça primordial à arte ${ }^{22}$. O entretenimento popular, o efeito "Hollywood", o transe televisivo, toda a parafernália que os teóricos da comunicação ligam ao "eros tecnológico", eis alguns dos tópicos que refletem esta imersividade alienante. Grande parte do debate sobre a distinção entre arte e entretenimento deverá, porventura, jogar-se neste contexto.

Sem dúvida, todas estas formas de literalização são intuídas quotidianamente, de modo mais ou menos consciente, por artistas, audiências e críticos, alimentando uma espécie de policiamento implícito do campo artístico e do seu senso comum, ou seja, regulando o que se considera ser a autenticidade estética em dado momento histórico.

Quanto ao sentido narrativo, aqui assumido como mecanismo fenomenológico da performatividade, também ele não constitui um princípio suficiente para uma descrição da experiência estética. Não se trata apenas de constatar que a performatividade, em sentido lato, colide com os propósitos da autenticidade artística ao desviar-se do real. Simplesmente, nem toda a performatividade é estética. A vida fenomenológica tem muito mais de performativo que de estético. Seria assim mesmo que toda a performatividade tivesse em vista a concretização estética (porque, mesmo então, haveria boas e más performances). Em todo o caso, ainda que a performatividade não seja critério suficiente, constitui ainda um requisito necessário da criação artística e, correlativamente, da experiência estética que lhe serve de propósito. Será sempre necessário passar pela performatividade (alimentada por um propósito autoral, um porvir) para que a arte possa, desde logo, ser fruída como tal. É esta passagem necessária pelo âmbito da performatividade que sentencia o realismo indireto da arte, tal como estivemos a descrevê-lo.

Nestes termos, o perigo mais subtil que se coloca ao cinema enquanto expressão artística não residirá tanto no recurso à narratividade (que nos afasta do real), mas na redução do cinema ao sentido literal (que nos afasta da performatividade). É certo que o real, de uma forma ou outra, mantém-se ainda como fundamento ontológico da autenticidade da arte; mas ele só poderá insinuar-se de forma indireta, como uma meta enviesada, inscrevendo-se num arco fenomenológico de retorno ao real a partir do recinto da performatividade. Entretanto, se a arte depende desta tensão entre o sentido narrativo e o sentido literal, então a narratividade reassume um peso fundamental na discussão sobre a arte e a experiência estética ${ }^{23}$. O sentido narrativo, enquanto mecanismo da performatividade, é o que sustém a distância em relação ao real para que se possa empreender um retorno ao real. A experiência estética instala-se neste delicado compromisso en-

22. Como nos recorda Umberto Eco: "Brecht exige que, para que o espetador se subtraia à eventual hipnose dos acontecimentos representados, se mantenha acesa a luz na sala e o público possa fumar" (Eco, 1989, p. 266).

23. Reabre-se, portanto, a possibilidade de conciliação entre o domínio da narratividade e esse regime estético que tão frequentemente se associa à recusa da representação e da narrativa. Naturalmente, as propostas de conciliação teórica entre a narratividade e a própria "vida" não são novas. Por exemplo, Marie-Claire Ropars-Wuilleumier propôs a distinção entre "história" (no seu desenrolar dramático) e "narrativa", relacionando esta última com o mesmo regime do "tempo vivido" que os puristas sensológicos do cinema associam aos filmes da imagem-tempo deleuziana. Segundo Ropars, "um filme pode contar uma história e não ser necessariamente uma narrativa" (Ropars, 1970, p. 30). E prossegue: "Aos olhos do espectador, o tempo é percebido como vivido à medida que a representação deixa de ser o suporte de uma ação imediatamente interpretável: aparecem então as diversas maneiras próprias ao tempo de passar sobre os seres" (Ibid., p. 142). 
tre a performatividade e o retorno ao real: ela constitui precisamente uma experiência performática do real. É neste sentido que se poderá começar a falar de autenticidade da obra de arte ${ }^{24}$.

\section{Bibliografia}

Ayfre, A. (1985). Neo-Realism and Phenomenology. In J. Hillier (org.), Cahiers du Cinema. The 1950s: Neo-Realism, Hollywood, New Wave (pp. 182-191). Cambridge: Harvard University Press.

Bazin, A. (1967). What is Cinema?. Berkeley: University of California Press.

Bazin, A. (1971). What is Cinema?, vol. II. Berkeley: University of California Press.

Bazin, A. (1983). Ontologia da Imagem Fotográfica. In I. Xavier (org.), A Experiência do Cinema (pp. 121-128). Rio de Janeiro: Edições Graal.

Benjamin, W. (1998). Understanding Brecht. London and New York: Verso.

Bergson, H. (1988). Ensaio sobre os Dados Imediatos da Consciência. Lisboa: Ed. 70.

Blanchot, M. (2005). O livro por vir. São Paulo: Martins Fontes.

Bordwell, D. (2008). Narration in the fiction film. London and New York: Routledge.

Brecht, B. (1978). Estudos sobre Teatro. Rio de Janeiro: Ed. Nova Fronteira

Brentano, F. (1995). Psychology from an Empirical Standpoint. London and New York: Routledge.

Bresson, R. (1995). Notes sur le cinématographe. Paris: Gallimard.

Chatman, S. (1978). Story and Discourse. Narrative Structure in Fiction and Film. New York: Cornell University Press.

Deleuze, G. (2004). A Imagem Movimento - Cinema 1. Lisboa: Assírio \& Alvim.

Deleuze, G. (2006). A Imagem Tempo - Cinema 2. Lisboa: Assírio \& Alvim.

Deleuze, G. (2011). Francis Bacon - Lógica da Sensação. Lisboa: Orfeu Negro.

Deleuze, G. \& Guattari, F. (1992). O que é a Filosofia?. Lisboa: Ed. Presença.

Durand, G. (2000). A Imaginação Simbólica. Lisboa: Ed. 70.

Eco, U. (1989). Obra Aberta. Lisboa: Difel.

Epstein, J. (1974). Écrits sur le cinema. Paris: Seghers.

Gaudreault, A. \& Jost, F. (org.) (2009). A Narrativa Cinematográfica. Brasília: Universidade de Brasília.

Grilo, J. M. (2010). As Lições do Cinema: Manual de Filmologia. Lisboa: Edições Colibri.

24. É também neste arco percetivo do intérprete perante o objeto artístico que a Aisthesis se distingue de outros regimes mais latos da sensologia. Na experiência estética, não há já possibilidade de demarcação entre os domínios do sensível e do inteligível. A Aisthesis não é mera depuração de um dos lados desta dicotomia, na forma de uma apologia do sensível contra o inteligível. A experiencia estética é, também ela, uma orientação fenomenológica do sentido. 
Heath, S. (2005). Comentário sobre "Ideias de Autoria". In F. P. Ramos (org.), Teoria Contemporânea do Cinema, vol. 1 - Pós-Estruturalismo e Filosofia Analítica (pp. 295-301). São Paulo: Ed. Senac.

Hume, D. (2004). Investigação sobre o Entendimento Humano. Lisboa: Ed.70.

Husserl, E. (2006). Investigaciones lógicas, 1. Madrid: Alianza Editorial.

Lacan, J. (1978). Le moi dans la théorie de Freud et dans la technique de la psychanalyse. Paris: Seuil.

Lyotard, J. (1971). Discours, figure. Paris: Klincksieck.

Kearney, R. (1984). Poétique du possible: phénoménologie hermenéutique de la figuration. Paris: Beauchesne.

Kracauer, S. (1997). Theory of Film: The Redemption of Physical Reality. New Jersey: Princeton University.

Martins, F. (2018). Between Formalism and Realism: The Case of Cinema. In F. Martins, N. Barros \& E. Vilela (org.), Unframing Archives (pp. 15-28). Porto: FLUP.

Martins, F. (2018). A Estética e as Sensologias. Cadernos IRI, (2). Vila do Conde: UniMAD/ESMAD

Martins, F. (2016). Sentido Narrativo - Da Formatividade à Performatividade. Porto: Afrontamento.

Martins, F. (org.) (2017). Trajetos da Narratividade. Porto: Ed. Universidade do Porto, Faculdade de Letras.

Miranda, J. B. (2012). Corpo e Imagem. Lisboa: Nova Vega.

Metz, C. (1968). Essais sur la signification au cinéma. Paris: Klincksieck.

Metz, C. (1974). Film Language: A Semiotics of the Cinema. New York: Oxford University Press.

Parente, A. (2005). Deleuze e as Virtualidades da narrativa cinematográfica. In F. P. Ramos (org.), Teoria Contemporânea do Cinema, vol. 1 - Pós-Estruturalismo e Filosofia Analítica (pp. 253-279). São Paulo: Ed. Senac.

Platão (2001). A República. Lisboa: Fundação Calouste Gulbenkian.

Ramos, F. P. (org.) (2005). Teoria Contemporânea do Cinema, vol. 1 - Pós-Estruturalismo e Filosofia Analítica. São Paulo: Ed. Senac.

Rancière, J. (2012). Os Intervalos do Cinema. Lisboa: Orfeu Negro.

Rancière, J. (2013). Béla Tarr. Lisboa: Orfeu Negro.

Rancière, J. (2014). A Fábula Cinematográfica. Lisboa: Orfeu Negro.

Ricoeur, P. (1986). Do Texto à Ação. Porto: RÉS-Editora.

Ricoeur, P. (2009). Teoria da Interpretação: O Discurso e o Excesso de Significação. Lisboa: Ed. 70.

Ropars-Wuilleumier, M. C. (1970). Littérature au cinéma. Paris: Armand Colin. 
Sartre, J. P. (2005). A Náusea. Mira-Sintra: Europa-América.

Shannon, C. (1993). Collected Papers. (Org. N. J. A. Sloane \& Aaron D. Wyner). New York: IEEE Press. 